\title{
Study of Tumor Necrosis Factor-Alpha-Induced Protein 3 Gene Single-Nucleotide Variants in JAK2 V617F-Positive Myeloproliferative Disorders: A Case-Control Study
}

\author{
Wafaa M. Abdelghany ${ }^{1 *(D)}$, Noha M. El Husseiny ${ }^{2,5}$, Gehad H. Fekry ${ }^{3}$, Osama H. Korayem ${ }^{4}$, Rehab Helmy ${ }^{1}$ \\ ${ }^{1}$ Department of Clinical and Chemical Pathology, Faculty of Medicine, Cairo University, Cairo, Egypt; ${ }^{2}$ Department of Clinical \\ Hematology, Faculty of Medicine, Cairo University, Cairo, Egypt; ${ }^{3}$ Department of Internal Medicine, Faculty of Medicine, Ain \\ Shams University, Cairo, Egypt; ${ }^{4}$ Department of Biotechnology and Life Sciences, Faculty of Postgraduate Studies for Advanced \\ Sciences, Beni-Suef University, Beni-Suef, Egypt; ${ }^{5}$ Armed Forces College of Medicine, Cairo, Egypt
}

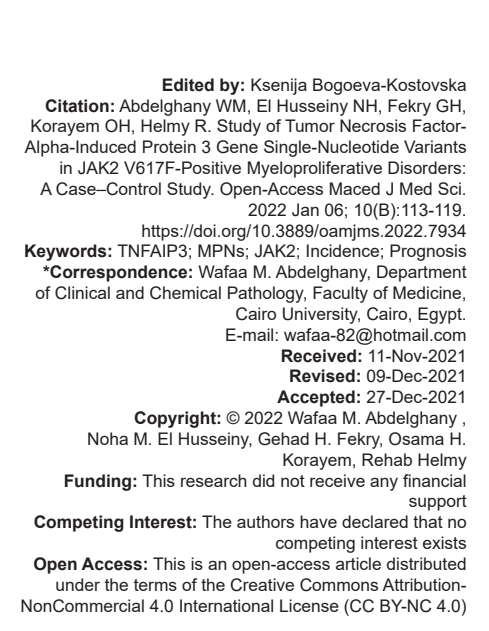

\section{Abstract}

BACKGROUND: Myeloproliferative neoplasms (MPNs) are Philadelphia-negative disorders involving polycythemia vera, essential thrombocythemia, and primary myelofibrosis. Although the JAK2 mutation is almost always involved, several other mutations are linked to MPNs risk and prognosis. Tumor necrosis factor-alphainduced protein 3 (TNFAIP3) genetic mutations are related to several cancers and autoimmune diseases.

AIM: Our study aimed to demonstrate the effects of rs2230926_T/G and rs5029939_C/G single-nucleotide variants (SNVs) of the TNFAIP3 gene on the risk and prognosis of JAK2 V617F-positive MPNs.

METHODS: In our study, 80 MPNs cases and 130 normal healthy controls were matched in age, gender, and race, and MPNs cases were followed for 3 years. TaqMan assay probes involved in real-time polymerase chain reaction were utilized for variant analysis.

RESULTS: The $r s 2230926$ and $r$ s5029939 SNVs were in modest linkage disequilibrium in MPNs cases. The observed frequencies of the $\mathrm{G}$ allele and its genotypes of both variants were more prevalent in MPNs patients than normal controls. The bleeding symptoms and the presence of splenomegaly were more prevalent in the heterozygous genotype and the combined $G$ involving genotypes, respectively. Overall survival was lower in G-containing genotypes of both variants, but only the rs5029939 SNV affected progression-free survival.

CONCLUSIONS: Our study revealed the association of G-containing genotypes of both $r$ 22230926 and $r s 5029939$ SNVs to the increased incidence as well as the poor clinical course and prognosis of JAK2 V617F-positive MPNs disorders in Egyptian ethnicity.

\section{Introduction}

Myeloproliferative neoplasms (MPNs) are BCR-ABL-negative disorders characterized by uncontrolled proliferation of hematopoietic progenitor cells. They are classified to various types including polycythemia vera (PV), essential thrombocythemia (ET), primary myelofibrosis (PMF) [1]. They may progress to secondary acute myeloid leukemia (AML) as well PV and ET may be complicated by secondary MF [2].

Although acquired JAK2 V617F mutation is found in more than $80 \%$ of MPNs disorders, JAK2 suppression is not being achieved as a permanent curative treatment line. Signaling pathways of JAK2 are targets of researchers to develop new diagnostic and treatment lines of MPNs [3]. The JAK2 signaling cascades are either directly through signal transducer and activator of transcription (STAT3, 5) or indirectly through nuclear factor kappa light chain enhancer of activated B cells (NF-кB), phosphatidylinositol 3-kinase, and mitogen-activated protein kinase (MAP kinase) [4].

Tumor necrosis factor-alpha-induced protein 3 gene (TNFAIP3) also called A20 is carried on $6 q 23.3$ chromosome. A20 is as an ubiquitin-editing enzyme;

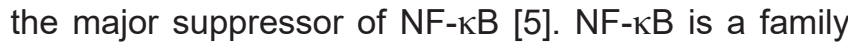
of transcription factors highly convenient to cellular functions, activation, and inflammatory reactions. $\mathrm{NF}-\kappa \mathrm{B}$ disturbance due to $\mathrm{A} 2$ gene defect by deletion or mutations has been related to malignant and autoimmune disorders [6]. NF-кB overexpression is noted in some classes of AML especially that with FLT3-ITD involvement [7] as well in myelodysplastic syndrome (MDS) [8].

TNFAIP3 genetic disturbance is found to be linked to B-cell non-Hodgkin's lymphoma (NHL) including follicular lymphoma, marginal zone lymphoma, diffuse large B-cell lymphoma, and primary mediastinal B-cell lymphoma, as well to HL and to T-cell lymphoma involving Sezary syndrome (SS) [9], [10]. 
Among TNFAIP3, single-nucleotide variants (SNVs) are rs2230926_T/G and rs5029939_C/G that were found to be in linkage disequilibrium (LD) in Caucasian population [11]. The rs2230926 is an exonic transversion with Phe127Cys amino acid exchange [5]. This change influences the suppressor function of A20 with responding to blockers of TNF in psoriasis. Furthermore, rs5029939, an intronic SNV of TNFAIP3, influences $A 20$ protein mRNA expression through NF-kB dysfunction [11].

Due to the scarcity of information on A20 defects in MPNs disorders, the study's hypothesis was to investigate the relationships between $r s 2230926$ T/G and rs5029939_C/G SNVs in JAK2 V617F-positive MPNs disorders in terms of MPNs incidence, clinical presentations, and behavior to suggest them as diagnostic and prognostic markers as well as therapy targets.

\section{Materials and Methods}

This case-control study involved 210 adult Egyptian participants. It was divided into two matched groups in age and gender, with 80 MPNs cases and 130 healthy controls. MPNs cases were selected among the patients attending the Hematology Outpatient Clinic of Kaser Alini Hospitals (Cairo University) from January 2017 to May 2018, followed up for 36 months. The inclusion criteria of the research involved adult Egyptian patients who were diagnosed with PRV, ET, or PMF diseases with a positive JAK2 V617F mutation. The exclusion criteria were chronic myeloid leukemia, double malignancies, JAK2 V617F-negative PRV, ET, and PMF and the other types of MPNs disorders such as mastocytosis and chronic neutrophilic leukemia. The control group was made up of people who came in for routine check-ups and had a free medical history, a normal examination, and good laboratory results.

The MPNs cases were diagnosed according to the World Health Organization (WHO) criteria for 2016 [2]. The enrolled subjects were exposed to history taking, full examinations, and laboratory analysis including complete blood count, coagulation studies, and chemistry tests with lactated dehydrogenase assay. Bone marrow (BM) aspirate and biopsy with reticulin stain were done to fulfill MPNs criteria and establish the grade of BM fibrosis from 0 to 3 . This classifies BM fibrosis as mild fibrosis if $<2$ and overt form in grades $\geq 2$.

Radiological investigations were involved, including abdominopelvic ultrasound and Doppler assessment of thrombotic presentations. Molecular studies were assessed on peripheral blood (PB) or BM samples for BCR-ABL to ensure its negativity as well as for JAK2 V617F mutation by quantitative real-time polymerase chain reaction (PCR) with the inclusion of its positive cases.
The treatment of MPNs cases was based on their types and risk stratification according to the 2016 WHO guidelines [12]. Low-dose aspirin was given to patients with any risk of thrombosis, while hydroxyurea was only given to patients with a high risk of thrombosis [13]. PRV patients undergo phlebotomy with a hematocrit of more than $45 \%$. Supportive treatment was administered in PMF cases according to the presenting manifestations.

All involved individuals accepted to share in the study by signing a written informed consent. The study was performed according to the human medical research ethics of the Declaration of Helsinki with the approval of the ethical committee of the Faculty of Medicine, Cairo University.

\section{Extraction of DNA}

EDTA anticoagulant-containing tubes were used to collect PB (2 mL) for DNA extraction. The tubes were kept at $-20^{\circ}$ till the process of extraction began. GeneJET mini kits (\# K0781) for DNA purification were used as directed by the manufacturer.

\section{TNFAIP3 variants genotyping}

Applied Biosystems StepOne real-time PCR apparatus was utilized to analyze the investigated variants. The genotyping was done by preparing master mix cocktail of $20 \mu \mathrm{L}$ final volume: $3.5 \mu \mathrm{L}$ of the extracted DNA, $0.5 \mu \mathrm{L}$ of SNV probe, $10 \mu \mathrm{L}$ of Thermo Fisher master mix, and $6 \mu \mathrm{L}$ of distilled water.

SNV TaqMan probes (Thermo Fisher scientific; \#4351379) were used. [VIC/FAM] GACTTGGTACTGAG GAAG G C G C T G T [ G/T] CAGCACGCTCAAGGAAACAGACACA was the rs2230926 sequence. The sequence for rs5029939 was [VIC/FAM] GTCACCTAAACTAGTTAGGAGCAGA[C/G] TTAAGCTAGAACCAAGGTCCCCTGG. The PCR amplification procedure began with a $30 \mathrm{~s}$ pre-PCR reading at $60^{\circ} \mathrm{C}$ followed by a $10 \mathrm{~min}$ hold at $95^{\circ} \mathrm{C}$. Following that, 45 amplification cycles of denaturation at $95^{\circ} \mathrm{C}$ and annealing/extension at $60^{\circ} \mathrm{C}$ for $30 \mathrm{~s}$ and $1 \mathrm{~min}$, respectively, were formed. Finally, post-PCR holding stage at $60^{\circ} \mathrm{C}$ for $30 \mathrm{~s}$ was done. Quality control was established done by repetition of genotyping on $\sim 10 \%$ of specimens and checking of the results by two observers without knowing the case-control condition.

\section{Statistical analysis}

A goodness-of-fit $(\chi 2)$ test was performed on Hardy-Weinberg equilibrium (HWE). Data were analyzed using IBMSPSSadvanced statistics version 17. Quantitative variables were expressed as mean and standard deviation or median and range. Qualitative data were formulated as frequency and percentage (\%). Qualitative input was 
evaluated using the Chi-square test or Fisher's exact test. For quantitative variables, two group comparisons were studied by a Student's t-test while an ANOVA test was used for three group comparisons. For risk assessment, odds ratio and $95 \%$ confidence interval were calculated. LD was mathematically assessed [14], [15]. Survival rates were calculated by the Kaplan-Meier method and the log-rank test. The hazard ratio was detected by the Cox regression test. $p=0.05$ or less was referred to as significant.

\section{Results}

\section{Subjects criteria}

The characteristics of the enrolled subjects are shown in Table 1. Regarding age and gender, no statistically significant difference between the cases and controls was detected.

Table 1: Demographic and clinical data of cases and controls

\begin{tabular}{|c|c|c|c|}
\hline Characteristics & Cases $(n=80)$ & Controls $(n=130)$ & $p$-value* \\
\hline \multicolumn{4}{|l|}{ Age (years) } \\
\hline Mean \pm SD & $52.68 \pm 10.899$ & $54.37 \pm 11.387$ & \multirow[t]{2}{*}{0.611} \\
\hline Range & $29-75$ & $29-76$ & \\
\hline \multicolumn{4}{|l|}{ Gender, n (\%) } \\
\hline Male & $45(56.25)$ & $58(44.6)$ & \multirow[t]{2}{*}{0.101} \\
\hline Female & $35(43.75)$ & $72(55.4)$ & \\
\hline \multicolumn{4}{|l|}{ Type of MPN, n (\%) } \\
\hline PRV & $42(52.5)$ & \multirow{3}{*}{ - } & \\
\hline ET & $20(25)$ & & \\
\hline PMF & $18(22.5)$ & & \\
\hline \multicolumn{4}{|c|}{ Clinical presentations, n (\%) } \\
\hline Bleeding & $10(12.5)$ & \multirow[t]{2}{*}{-} & \\
\hline Thrombosis & $17(21.3)$ & & \\
\hline \multicolumn{4}{|l|}{ Organomegaly, n (\%) } \\
\hline Hepatomegaly & $15(18.8)$ & \multirow[t]{2}{*}{-} & \\
\hline Splenomegaly & $52(65)$ & & \\
\hline \multicolumn{4}{|c|}{ Laboratory data, median (Range) } \\
\hline RBCs (million/mm³ & $5.75(2.4-8.9)$ & \multirow{5}{*}{-} & \\
\hline HCT (\%) & $46.5(18.5-70)$ & & \\
\hline $\operatorname{TLC}\left(\times 10^{3} / \mathrm{mm}^{3}\right)$ & $12.30(2.10-58)$ & & \\
\hline PLTs $\left(\times 10^{3} / \mathrm{mm}^{3}\right)$ & $673(30-1525)$ & & \\
\hline JAK2 (\%) & $32.60(3.125-96.1)$ & & \\
\hline \multirow{2}{*}{\multicolumn{4}{|c|}{$\begin{array}{l}\text { Grades of fibrosis at diagnosis, } \\
n(\%)\end{array}$}} \\
\hline & & & \\
\hline 0 & $23(28.7)$ & \multirow[t]{4}{*}{-} & \\
\hline I & $24(30)$ & & \\
\hline II & $21(26.3)$ & & \\
\hline III & $12(15)$ & & \\
\hline \multicolumn{4}{|l|}{ Progression, n (\%) } \\
\hline Progression to MF & $9(11.3)$ & & \\
\hline $\begin{array}{l}\text { Progression to acute } \\
\text { leukemia }\end{array}$ & $2(2.5)$ & & \\
\hline Death, n (\%) & $10(8)$ & & \\
\hline
\end{tabular}

The MPNs cases were classified into PRV, ET, and PMF. Bleeding and thrombotic manifestations were present in all three categories of MPNs. As bleeding symptoms were presented in 10 cases, in the form of epistaxis in one case, bleeding per gum in five patients, and four cases manifested by bleeding per rectum. Thrombotic events were present in 17 patients, as portal vein thrombosis in five cases, gangrene of the toes in nine cases, stroke in two patients, and myocardial infarctions were detected in only one case (Table 1).

Organomegaly was variable in our cases, in the form of hepatomegaly and/or splenomegaly. Grades of $\mathrm{BM}$ fibrosis by reticulin stain on BMB were assessed at presentation as well as on follow-up. Progression of the disease occurred to secondary MF and acute leukemia. In 3 years of follow-up, about $8 \%$ of MPNs cases died (Table 1).

Genotyping of rs2230926_T/G and rs5029939_C/G in cases and controls

In concordance to HWE, the observed genotypic frequencies were not statistically different than the expected ones in both cases and controls $(p>0.05)$. Both variants were in modest LD in the MPNs cases $\left(D^{\prime}=0.5\right.$ and $\left.r^{2}=0.2\right)$.

The $\mathrm{G}$ allele and its containing genotypes of both variants were of high risk for MPNs incidence with p $<0.05$ (Table 2).

\section{Correlation of rs2230926 T/G and rs5029939_C/G to patients' characteristics}

The G-containing genotypes of both variants were associated with worse clinical manifestations and poor prognostic value in MPNs disorders. The TG genotype of $r s 2230926$ and the CG genotype of rs5029939 were statistically significant and associated with the existence of bleeding symptoms. As well, the TG+GG genotypes of rs2230926 and the GG+CG genotypes of rs5029939 were linked to the presence of splenomegaly (Tables 3 and 4).

For both variants, no significant difference was found regarding age, sex, type of MPNs, grades of BM fibrosis, thrombosis occurrence, presence of hepatomegaly, or the progression of disease to MF or acute transformation in their different genotypic modalities (Tables 3 and 4).

\section{Overall survival (OS)}

The number of deaths was significantly higher in G-containing genotypes of both variants with $p<0.05$ (Tables 3 and 4). The mean OS of MPNs cases was higher in the TT genotype than in the TG and GG genotypes for rs2230926, 35.430, 32.595, and 27.940 months, respectively, with $p=0.002$. The TG+GG genotype was associated with an increased risk of death $(\mathrm{HR}=8.826$, $\mathrm{p}=0.006$, and 95\% Cl = 1.873-41.594) (Figure 1).

Regarding rs5029939, the OS was prolonged in the CC genotype more than that found in CG and GG genotypes, with a mean of $35.632,32.387$, and 29.283 months, respectively; $p=0.001$. The CG+GG genotypes carried a higher risk for mortality than the CC genotype $(\mathrm{HR}=16.935, \mathrm{p}=0.007$, and $95 \%$ $\mathrm{Cl}=2.144-133.768)($ Figure 1).

\section{Progression-free survival}

For rs2230926, the mean of progressionfree survival (PFS) was not different between TT, TG, and GG, being 34.457, 33.593, and 27.620 months, respectively, with $p=0.2$. In rs5029939, the mean PFS in G-containing genotypes $G G$ and $C G$ was 


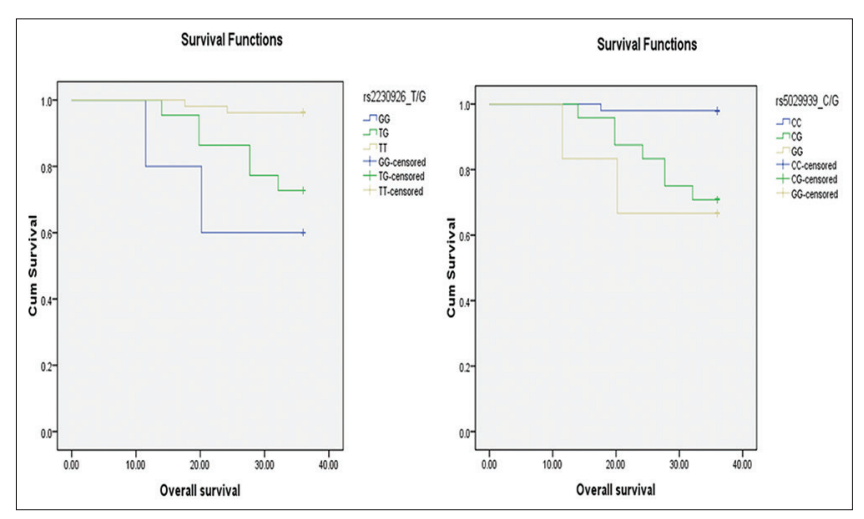

Figure 1: OS of rs2230926_T/G and rs5029939_C/G

lower than in CC genotypes at 27.367, 32.982, and 34.918 months, respectively $(p=0.011)$. As well, the CG+GG genotypes carried a higher risk for progression than the CC genotype $(\mathrm{HR}=3.3, \mathrm{p}=0.037$, and $95 \%$ $\mathrm{Cl}=1.077-10.110)$ (Figure 2).

Table 2: Genotyping of rs2230926_T/G and rs5029939_C/G in the studied groups

\begin{tabular}{|c|c|c|c|c|}
\hline \multirow[t]{2}{*}{ Characteristics } & Cases $(n=80)$ & Controls $(n=130)$ & \multirow[t]{2}{*}{$p$-value ${ }^{*}$} & \multirow[t]{2}{*}{ OR $(95 \% \mathrm{Cl})$} \\
\hline & $n(\%)$ & $n(\%)$ & & \\
\hline \multicolumn{5}{|l|}{ rs2230926_T/G } \\
\hline \multicolumn{5}{|l|}{ Genotypes } \\
\hline $\mathrm{TT}$ & $53(66.3)$ & $106(81.5)$ & Reference & \\
\hline TG & $22(27.5)$ & $23(17.7)$ & & \\
\hline GG & $5(6.3)$ & $1(0.8)$ & $0.011^{*}$ & \\
\hline$T G+G G$ & $27(33.8)$ & $24(18.5)$ & $0.012^{*}$ & $\begin{array}{l}2.250 \\
(1.185-4.272)\end{array}$ \\
\hline$P_{\text {HWE }}$ & 0.453 & 0.458 & & \\
\hline Alleles & & & & \\
\hline $\mathrm{T}$ & $128(80)$ & $235(90.4)$ & & \\
\hline G & $32(20)$ & $25(9.6)$ & $0.003^{*}$ & $\begin{array}{l}2.350 \\
(1.335-4.138)\end{array}$ \\
\hline \multicolumn{5}{|l|}{ rs5029939_C/G } \\
\hline Genotypes & & & & \\
\hline $\mathrm{CC}$ & $50(62.5)$ & $103(79.2)$ & Reference & \\
\hline CG & $24(30)$ & $26(20)$ & & \\
\hline GG & $6(7.5)$ & $1(0.8)$ & $0.005^{*}$ & \\
\hline$C G+G G$ & $30(37.5)$ & $27(20.8)$ & $0.008^{*}$ & $\begin{array}{l}2.289 \\
(1.231-4.255)\end{array}$ \\
\hline $\begin{array}{c}P_{\text {HWE }} \\
\text { Alleles }\end{array}$ & 0.979 & 0.898 & & \\
\hline C & $124(77.5)$ & $232(89.2)$ & & \\
\hline G & $36(22.5)$ & $28(10.8)$ & $0.001^{*}$ & $\begin{array}{l}2.406 \\
(1.402-4.127)\end{array}$ \\
\hline
\end{tabular}

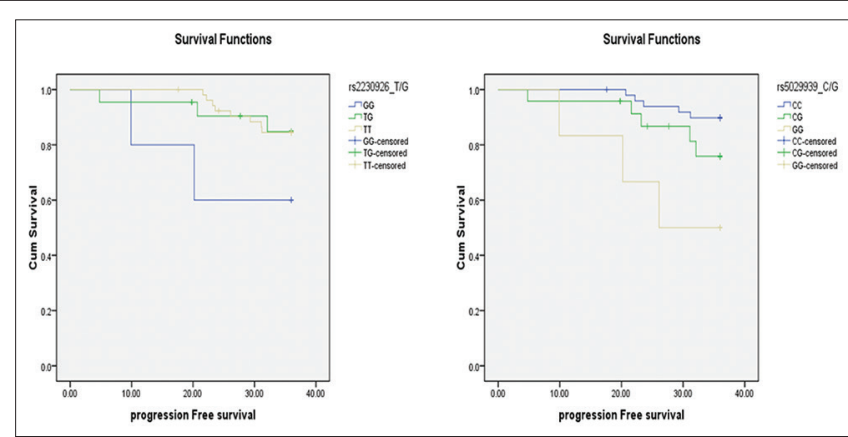

Figure 2: PFS of rs2230926_T/G and rs5029939_C/G

\section{Discussion}

Philadelphia-negative MPNs are characterized by myeloid clonal proliferation with the JAK2 mutation as one of their major diagnostic criteria [1]. The inflammatory deregulation genes are also included in MPNs' pathogenesis and progression: BCL6, CXCR1, TP53, CD40LG, and TNFAIP3 [16]. The TNFAIP3 gene is a major genetic control gene for the inflammatory signaling pathway through NF- $\mathrm{kB}$ suppression and apoptosis inhibitor induced by TNF [17].

Our study revealed the association of $r s 2230926$ and rs5029939 SNVs of the TNFAIP3 gene to MPNs incidence and prognosis in the Egyptian population. To the best of our knowledge, it is the first research concerned with investigating A20 SNVs in MPNs. In this study, we analyzed both variants by real-time PCR; the sequencing of results for confirmation was done in various previous researches. As Zhou et al. confirmed the results of both variants by sequencing after PCR-restriction fragment length polymorphism analysis in relation to immune thrombocytopenia (ITP) of the Chinese population [18].

For rs2230926, the TG and GG genotypes were more common in cases $(27.5 \%$ and $6.3 \%$,

Table 3: Relations of $r s 2230926$ _T/G genotypes to demographic and clinical data in MPNs cases

\begin{tabular}{|c|c|c|c|c|c|c|c|}
\hline Characteristics & $\begin{array}{l}\text { TT }(n=53) \\
n(\%)\end{array}$ & $\begin{array}{l}\text { TG }(n=22) \\
n(\%)\end{array}$ & $\begin{array}{l}G G(n=5) \\
n(\%)\end{array}$ & p-value ${ }^{*}$ & $\begin{array}{l}\mathrm{TT}(\mathrm{n}=53) \\
\mathrm{n}(\%)\end{array}$ & $\begin{array}{l}\text { TG+GG (n=27) } \\
\mathrm{n}(\%)\end{array}$ & $p$-value ${ }^{*}$ \\
\hline \multicolumn{8}{|l|}{ Age } \\
\hline Mean \pm SD & $53.66 \pm 11.109$ & $51.27 \pm 11.05$ & $48.40 \pm 7.335$ & 0.462 & $53.66 \pm 11.109$ & $50.74 \pm 10.402$ & 0.260 \\
\hline Range & $30-75$ & $29-67$ & $41-58$ & & $30-75$ & $29-67$ & \\
\hline \multicolumn{8}{|l|}{ Sex } \\
\hline Male & $30(56.6)$ & $13(59.1)$ & $2(40)$ & 0.737 & $30(56.6)$ & $15(55.6)$ & 0.929 \\
\hline Female & $23(43.4)$ & $9(40.9)$ & $3(60)$ & & $23(43.4)$ & $12(44.4)$ & \\
\hline \multicolumn{8}{|l|}{ Type of MPN } \\
\hline PRV & $30(56.6)$ & $12(54.5)$ & $0(0$ & 0.150 & $30(56.6)$ & $12(44.4)$ & 0.487 \\
\hline ET & $13(24.5)$ & $5(22.7)$ & $2(40)$ & & $13(24.5)$ & $7(25.9)$ & \\
\hline PMF & $10(18.9)$ & $5(22.7)$ & $3(60)$ & & 10 (18.9) & $8(29.6)$ & \\
\hline \multicolumn{8}{|l|}{ Clinical presentations } \\
\hline Thrombosis & $11(20.8)$ & $5(22.7)$ & $1(20)$ & 0.980 & $11(20.8)$ & $6(22.2)$ & 0.879 \\
\hline Bleeding & $3(5.7)$ & $7(31.8)$ & $0(0)$ & $0.005^{*}$ & $3(5.7)$ & $7(25.9)$ & $0.010^{*}$ \\
\hline \multicolumn{8}{|l|}{ Organomegaly } \\
\hline Hepatomegaly & $11(20.8)$ & $3(13.6)$ & $1(20)$ & 0.770 & $11(20.8)$ & $4(14.8)$ & 0.520 \\
\hline Splenomegaly & $29(54.7)$ & $18(81.8)$ & $5(100)$ & $0.019^{*}$ & $29(54.7)$ & $23(85.2)$ & $0.007^{*}$ \\
\hline \multicolumn{8}{|l|}{ Grades of fibrosis at diagnosis, $\mathrm{n}(\%)$} \\
\hline Mild $(0+I)$ & $32(60.4)$ & $13(59.1)$ & $2(40)$ & 0.676 & $32(60.4)$ & $15(55.6)$ & 0.679 \\
\hline Overt (II+III) & 21 (39.6) & $9(40.9)$ & $3(60)$ & & $21(39.6)$ & $12(44.4)$ & \\
\hline \multicolumn{8}{|l|}{ Progression } \\
\hline Progression to MF & $7(13.2)$ & $1(4.5)$ & $1(20)$ & 0.158 & 7 (13.2) & $2(7.4)$ & 0.467 \\
\hline Progression to acute leukemia & $1(1.9)$ & $1(4.5)$ & $0(0)$ & 0.745 & $1(1.9)$ & $1(3.7)$ & 0.623 \\
\hline Deaths & $2(3.77)$ & $6(27.27)$ & $2(40)$ & $0.003^{*}$ & $2(3.77)$ & $8(29.63)$ & $0.001^{*}$ \\
\hline
\end{tabular}


Table 4: Relations of $r s 5029939$ C $/ G$ genotypes to demographic and clinical data of MPNs cases

\begin{tabular}{|c|c|c|c|c|c|c|c|}
\hline Characteristics & $\begin{array}{l}\text { CC }(n=50) \\
n(\%)\end{array}$ & $\begin{array}{l}\text { CG (n=24) } \\
n(\%)\end{array}$ & $\begin{array}{l}\mathrm{GG}(\mathrm{n}=6) \\
\mathrm{n}(\%)\end{array}$ & p-value ${ }^{*}$ & $\begin{array}{l}\mathrm{CC}(\mathrm{n}=50) \\
\mathrm{n}(\%)\end{array}$ & $\begin{array}{l}\text { CG+GG (n=30) } \\
n(\%)\end{array}$ & $p$-value ${ }^{*}$ \\
\hline \multicolumn{8}{|l|}{ Age } \\
\hline Mean \pm SD & $52.24 \pm 11.231$ & $53.17 \pm 11.343$ & $54.33 \pm 6.501$ & \multirow[t]{2}{*}{0.878} & $52.24 \pm 11.231$ & $53.40 \pm 10.467$ & \multirow[t]{2}{*}{0.648} \\
\hline Range & $29-75$ & $33-71$ & $45-63$ & & $29-75$ & $33-71$ & \\
\hline \multicolumn{8}{|l|}{ Sex } \\
\hline Male & $29(58)$ & $14(58.3)$ & $2(33.3)$ & \multirow[t]{2}{*}{0.5} & $29(58)$ & $16(53.3)$ & \multirow[t]{2}{*}{0.684} \\
\hline Female & $21(42)$ & $10(41.7)$ & $4(66.7)$ & & $21(42)$ & $14(46.7)$ & \\
\hline \multicolumn{8}{|l|}{ Type of MPN } \\
\hline PRV & $30(60)$ & $11(45.8)$ & $1(16.7)$ & \multirow[t]{3}{*}{0.108} & $30(60)$ & $12(40)$ & \multirow[t]{3}{*}{0.209} \\
\hline ET & $10(20)$ & $6(25)$ & $4(66.7)$ & & $10(20)$ & $10(33.3)$ & \\
\hline PMF & $10(20)$ & $7(29.2)$ & $1(16.7)$ & & $10(20)$ & $8(26.7)$ & \\
\hline \multicolumn{8}{|l|}{ Clinical presentations } \\
\hline Thrombosis & $9(18)$ & $5(20.8)$ & $3(50)$ & 0.194 & $9(18)$ & $8(26.7)$ & 0.359 \\
\hline Bleeding & $1(2)$ & $9(37.5)$ & $0(0)$ & $<0.001^{*}$ & $1(2)$ & $9(30)$ & $<0.001^{*}$ \\
\hline \multicolumn{8}{|l|}{ Organomegaly } \\
\hline Hepatomegaly & $12(24)$ & $2(8.3)$ & $1(16.7)$ & 0.268 & $12(24)$ & $3(10)$ & 0.120 \\
\hline Splenomegaly & $27(54)$ & $21(87.5)$ & $4(66.7)$ & $0.018^{*}$ & $27(54)$ & $25(83.3)$ & $0.008^{*}$ \\
\hline \multicolumn{8}{|l|}{ Grades of fibrosis at diagnosis, $\mathrm{n}(\%)$} \\
\hline Mild $(0+1)$ & $30(60)$ & $13(54.2)$ & $4(66.7)$ & \multirow[t]{2}{*}{0.821} & $30(60)$ & $17(56.7)$ & \multirow[t]{2}{*}{0.769} \\
\hline Overt (II+III) & $20(40)$ & $11(45.8)$ & $2(33.3)$ & & $20(40)$ & $13(43.3)$ & \\
\hline \multicolumn{8}{|l|}{ Progression } \\
\hline Progression to MF & $4(8)$ & $3(12.5)$ & $2(33.3)$ & 0.340 & $4(8)$ & $5(16.7)$ & 0.319 \\
\hline Progression to acute leukemia & $1(2)$ & $1(4.2)$ & $0(0)$ & 0.787 & $1(2)$ & $1(3.3)$ & 0.712 \\
\hline Death & $1(2)$ & $7(29.2)$ & $2(33.3)$ & $0.001^{*}$ & $1(2)$ & $9(30)$ & $<0.001^{*}$ \\
\hline
\end{tabular}

respectively) than in controls $(17.7 \%$ and $0.8 \%$, independently), while the TT genotype was more common in controls $(81.5 \%)$ than in cases $(66.3 \%)$; $\mathrm{p}=0.01$. The combined $(\mathrm{TG}+\mathrm{GG})$ genotypes carried a 2.25 higher risk of MPN occurrence than the TT genotype $(p=0.012$, OR $=2.250$, and $95 \% \mathrm{Cl}=1.185$ $4.272)$. The $\mathrm{G}$ allele was more prevalent in cases $(20 \%)$ than controls $(9.6 \%)$ to be at a risk for MPN incidence $(\mathrm{OR}=2.350$ and $95 \% \mathrm{Cl}=1.335-4.138)$.

For rs5029939, CG+GG genotype frequencies were $37.5 \%$ in cases and $20.8 \%$ in controls, increasing the risk of MPNs incidence $(p=0.008, O R=2.289$, and $95 \% \mathrm{Cl}=1.231-4.255)$. As well, the $\mathrm{G}$ allele was found to raise MPNs occurrence $(p=0.001$, OR $=2.406$, and $95 \% \mathrm{Cl}=1.402-4.127)$.

In agreement with our study, Kato et al. [9] study provided a wide genomic analysis, including A20 genetic variants in relation to malignant tumors, $\mathrm{NHL}$, and HL. They found that TNFAIP3 genetic variants were prevalent in $21.8 \%$ of mucosa-associated tissue lymphoma as well as in $33.3 \%$ of the nodular sclerosis type of HL. In addition, NF-кB pathway genetic disruption was detected in $40 \%$ of B-cell lymphoma.

Our study documented the presence of LD between rs2230926 and rs5029939 in Egyptian MPNs cases $\left(D=0.5\right.$ and $\left.r^{2}=0.2\right)$. This is in agreement with Bates et al.'s meta-analysis that confirmed the presence of LD between both variants in Caucasian ethnicity $\left(r^{2}=0.99\right)$ [11]. In addition, Zhou et al. detected their linkage in Chinese with $r^{2}=0.108$ and $D^{\prime}=0.359$ [18].

Our results for $r$ 2230926 genotypic modalities to clinical manifestations of MPNs revealed that TG and GG genotypes were more frequent in cases presented with splenomegaly than those found with the TT genotype ( $p=0.019)$. Bleeding symptoms were more frequent in cases with TG genotype $(31.8 \%)$ than in those with TT genotype $(5.7 \%)(p=0.005)$. Regarding OS of MPNs cases, it was more prolonged in the TT genotype than that calculated for $T G$ and $G G$ genotypes ( $p=$ 0.002 ). The combined TG+GG genotypes had an 8.826 hazard ratio for mortality compared to the TT genotype ( $p=0.006$ and $95 \% \mathrm{Cl}=1.873-41.594)$. There was no statistically significant relationship between rs2230926 genetic types and PFS.

Regarding rs $5029939,37.5 \%$ of cases with the CG genotype had bleeding symptoms while they were present in only $2 \%$ of the GG genotype ( $p<0.001$ ). Splenomegaly was detected in $54 \%, 87.5 \%$, and $66.7 \%$ of CC, CG, and GG genotypes, respectively ( $p=0.018$ ). The OS was reduced in cases with $C G$ and $G G$ genotypes than in those with CC genotypes $(p=0.001)$. The CG+GG genotypes had a higher mortality risk than the CC genotype (HR $=16.935, p=0.007$, and $95 \%$ $\mathrm{Cl}=2.144-133.768)$. PFS was also lower in $\mathrm{CG}+\mathrm{GG}$ genotypes compared to $\mathrm{CC}$ ones $(\mathrm{HR}=3.3, \mathrm{p}=0.037$, and $95 \% \mathrm{Cl}=1.077-10.110$ ).

No statistical significance was found regarding the different genotypes of both variants to age, sex, different types of MPNs, occurrence of thrombosis, presence of hepatomegaly, grades of BM fibrosis, or progression of disease to either MF or acute leukemia.

Concomitant to our results, Braun et al. [10] studied the association of A20 genetic deletion/mutation with subsequent NF-KB deregulation in SS prognosis. They found that dysfunction of A20, either mono or biallelic, was linked to malignant T-cell proliferation and was more frequent in SS cases (6/13). The amount of mRNA of A20 and its protein expression in SS cells with A20 deletion was examined to be found not detected in biallelic deletion and weakly expressed in monoallelic deletion. No cellular toxicity in an A20 deficient cell line (SeAx A20) after induction of A20 was detected in comparison to the reference empty cell line (SeAx MOCK). The $S$ phase of SeAx A20 was less than that found in SeAx MOCK with $p=0.01$. As well, SeAx A20 was more in $\mathrm{G} 1 / \mathrm{G} 0$ and less in $\mathrm{G} 2 / \mathrm{M}$ than what was found in SeAx MOCK ( $p=0.006$ and 0.004 , respectively). 
In addition, Zhou et al. [19] discussed the $\mathrm{NF}-\kappa \mathrm{B}$ deregulation in $\mathrm{AML}$ as a target for therapy. Bortezomib as an NF- $\mathrm{KB}$ inhibitor has entered into various clinical trials in the treatment of $A M L$, either alone or in combination with other drugs, with marked improvement in remission rates.

Similarly, Skov et al. [16] examined by microarray the genetic expression of patients diagnosed as PRV, ET, and PMF who were receiving interferon-alpha 2 (IFN- $\alpha 2$ ) therapy. IFN- $\alpha 2$ reduces the inflammatory immune reactions by regulation of its responsible genes. Skov et al. documented the induction of TNFAIP3 gene expression in PRV and PMF cases receiving IFN- $\alpha 2$ treatment to confirm that TNFAIP3 appeared to play an important role in MPNs' pathogenesis and prognosis.

Inflammation is one of the factors promoting MPNs development and affects its prognosis. PMF is found to be correlated with inflammatory cytokines, including IL-6, C-reactive protein, and TNF [20]. MPL W515L and JAK2 V617F-positive MPNs have been linked to inflammatory pathway signaling mediators such as PI3 kinase, MAP kinase, and NF-kB [21], [22].

The rs2230926_T/G is the most common variant of $\mathrm{A} 20$ gene in autoimmune disorders such as ITP, systemic lupus erythematosus (SLE), and rheumatoid arthritis [23], [24]. It leads to phenylalanine to cysteine amino acid exchange at position 127 in exon 3 of the A20 gene [25]. This substitution dampens the anti-inflammatory functions of TNFAIP3, which is also involved in lymphoma of B- and T-cell origin [5]. The rs5029939_C/G in intron 2 of A20 disrupts the expression protein level of the TNFAIP3 gene with activation of the $N F-\kappa B$ signaling pathway and is related to SLE and systemic sclerosis pathogenesis and behavior [26].

The present study is the initial research of SNVs of the A20 gene in MPNs disorders. It gives the first step in clarifying the role of TNFAIP3 genetic variants in MPNs. It represents a key toward further studies for more investigations into their roles in the diagnosis and management of MPNs.

The limitations of our study were due to the absence of financial support, which will be fulfilled in the future research. It is presented in the lack of a confirmatory method for our results, but we depended on its verification by sequencing in other researches of different populations.

\section{Conclusions}

Our study provides the first analysis of TNFAIP3 SNVs in MPNs incidence and prognosis. The rs2230926_T/G and rs5029939_C/G SNVs were found to be in LD in Egyptian MPNs cases. The G-containing genotypes of both variants were consistent with bleeding symptoms, the presence of splenomegaly, and poor survival rates. The PFS was lower in $\mathrm{G}$ involved genotypes of rs5029939, which was not observed in rs2230926 genotypes.

\section{References}

1. Chen Y, Fang F, HuY, Liu Q, Bu D, Tan M, etal. The polymorphisms in LNK gene correlated to the clinical type of myeloproliferative neoplasms. PLoS One. 2016;11(4):e0154183. https://doi. org/10.1371/journal.pone.0154183 PMid:27111338

2. Passamonti $F$, Maffioli $M$. Update from the latest $W H O$ classification of MPNs: A user's manual. Hematology Am Soc Hematol Educ Program. 2016;2016(1):534-42. https://doi. org/10.1182/asheducation-2016.1.534 PMid:27913526

3. Uras IZ, Maurer B, Nivarthi H, Jodl P, Kollmann K, PrchalMurphy M, et al. CDK6 coordinates JAK2 ${ }^{\mathrm{V} 617 \mathrm{~F}}$ mutant MPN via NF-KB and apoptotic networks. Blood. 2019;133(15):1677-90. https://doi.org/10.1182/blood-2018-08-872648 PMid:30635286

4. Fisher DA, Malkova O, Engle EK, Miner CA, Fulbright MC, Behbehani GK, et al. Mass cytometry analysis reveals hyperactive NF kappa B signaling in myelofibrosis and secondary acute myeloid leukemia. Leukemia. 2017;31(9):1962-74. https:// doi.org/10.1038/leu.2016.377 PMid:28008177

5. Zhu L, Zhang F, Shen Q, Chen S, Wang X, Wang L, et al Characteristics of A20 gene polymorphisms in T-cell acute lymphocytic leukemia. Hematology. 2014;19(8):448-54. https:// doi.org/10.1179/1607845414Y.0000000160 PMid:24611736

6. Park MH, Hong JT. Roles of NF-kB in cancer and inflammatory diseases and their therapeutic approaches. Cells. 2016;5(2):15. https://doi.org/10.3390/cells5020015 PMid:27043634

7. Figueroa ME, Lugthart $\mathrm{S}$, Li $\mathrm{Y}$, Erpelinck-Verschueren $\mathrm{C}$ Deng $\mathrm{X}$, Christos PJ, et al. DNA methylation signatures identify biologically distinct subtypes in acute myeloid leukemia. Cancer Cell. 2010;17(1):13-27. https://doi.org/10.1016/j. ccr.2009.11.020

PMid:20060365

8. Grosjean-Raillard J, Tailler M, Ades L, Perfettini JL, Fabre C, Braun T, et al. ATM mediates constitutive NF-kappaB activation in high-risk myelodysplastic syndrome and acute myeloid leukemia. Oncogene. 2009;28(8):1099-109. https://doi. org/10.1038/onc.2008.457 PMid: 19079347

9. Kato M, Sanada M, Kato I, Sato Y, Takita J, Takeuchi K, et al Frequent inactivation of A20 in B-cell lymphomas. Nature. 2009;459(7247):712-6. https://doi.org/10.1038/nature07969 PMid:19412163

10. Braun FC, Grabarczyk P, Möbs M, Braun FK, Eberle J, Beyer M, et al. Tumor suppressor TNFAIP3 (A20) is frequently, deleted in Sézary syndrome. Leukemia. 2011;25(9):1494-501. https://doi. org/10.1038/leu.2011.101

PMid:21625233

11. Bates JS, Lessard CJ, Leon JM, Nguyen T, Battiest LJ, 
Rodgers $\mathrm{J}$, et al. Meta-analysis and imputation identifies a $109 \mathrm{~kb}$ risk haplotype spanning TNFAIP3 associated with lupus nephritis and hematologic manifestations. Genes Immun. 2009;10(5):470-7. https://doi.org/10.1038/gene.2009.31

PMid:19387456

12. Kim SY, Bae SH, Bang SM, Ki-Seong Eom KS, Hong J, Jang S, et al. The 2020 revision of the guidelines for the management of myeloproliferative neoplasms. Korean $\mathrm{J}$ Intern Med. 2021;36(1):45-62. https://doi.org/10.3904/kjim.2020.319 PMid:33147902

13. Alvarez-Larrán A, Besses C. Antiplatelet therapy in the management of myeloproliferative neoplasms. Curr Hematol Malig Rep. 2014;9(4):319-23. https://doi.org/10.1007/s11899-014-0226-1 PMid:25120015

14. Zapata C. Linkage disequilibrium measures for fine-scale mapping of disease loci are revisited. Front Genet. 2013;4:228. https://doi.org/10.3389/fgene.2013.00228 PMid:24204380

15. Berger $S$, Schlather $M$, de los Campos $G$, Weigend $S$, Preisinger R, Erbe $\mathrm{M}$, et al. A scale-corrected comparison of linkage disequilibrium levels between genic and non-genic regions. PLoS One. 2015;10(10):e0141216. https://doi. org/10.1371/journal.pone.0141216

PMid:26517830

16. Skov V, Riley C, Thomassen M, Kjær L, Larsen TS, Bjerrum OW, et al. Interferon-alfa2 treatment of patients with polycythemia vera and related neoplasms influences deregulated inflammation and immune genes in polycythemia vera and allied neoplasms. Blood. 2018;132(1):5490. https://doi.org/10.1182/ blood-2018-99-118690

17. Fisher DA, Fowles JS, Zhou A, Oh ST. Inflammatory pathophysiology as a contributor to myeloproliferative neoplasms. Front Immunol. 2021;12:683401. https://doi. org/10.3389/fimmu.2021.683401

PMid:34140953

18. Zhou H, Yang J, Liu L, Zhang D, Zhou K, Li H, et al. The polymorphisms of tumor necrosis factor-induced protein 3 gene may contribute to the susceptibility of chronic primary immune thrombocytopenia in Chinese population. Platelets. 2016;27(1):2631. https://doi.org/10.3109/09537104.2015.1022142

PMid:25806576
19. Zhou J, Ching YQ, Chng WJ. Aberrant nuclear factor-kappa B activity in acute myeloid leukemia: From molecular pathogenesis to therapeutic target. Oncotarget. 2015;6(8):5490-500. https:// doi.org/10.18632/oncotarget.3545

PMid:25823927

20. Fisher DA, Miner CA, Engle EK, Hu H, Collins TB, Zhou A, et al. Cytokine production in myelofibrosis exhibits differential responsiveness to JAKSTAT, MAP kinase, and NFkappaB signaling. Leukemia. 2019;33(8):1978-95. https://doi. org/10.1038/s41375-019-0379-y

PMid:30718771

21. Kleppe M, Koche R, Zou L, van Galen P, Hill CE, Dong L, et al. Dual targeting of oncogenic activation and inflammatory signaling increases therapeutic efficacy in myeloproliferative neoplasms. Cancer Cell. 2017;21:489-501. https://doi. org/10.1016/j.ccell.2017.11.009

PMid:29249691

22. Jacquelin $S$, Straube J, Cooper L, Vu T, Song A, Bywater $M$, et al. Jak2V617F and dnmt3a loss cooperate to induce myelofibrosis through activated enhancer-driven inflammation. Blood. 2018;132(26):2707-21. https://doi.org/10.1182/ blood-2018-04-846220

PMid:30366920

23. Musone SL, Taylor KE, Nititham J, Chu C, Poon A, Liao W, et al. Sequencing of TNFAIP3 and association of variants with multiple autoimmune diseases. Genes Immun. 2011;12(3):17682. https://doi.org/10.1038/gene.2010.64

PMid:21326317

24. Zanaty $\mathrm{MI}$, Korayem OH, Meabed MH, El Demerdash D, Abdelghany WM. Impact of TNFAIP3 genetic polymorphisms on primary immune thrombocytopenia in Egyptian adult: Casecontrol study. Open Access Maced J Med Sci. 2021.

25. Swinkels M, Rijkers M, Voorberg J, Vidarsson G, Leebeek FW, Jansen AJ. Emerging concepts in immune thrombocytopenia. Front Immunol. 2018;9:880. https://doi.org/10.3389/ fimmu.2018.00880

PMid:29760702

26. Broen JCA, Coenen MJ, Radstake TR. Genetics of systemic sclerosis: An update. Curr Rheumatol Rep. 2012;14(1):11-21. https://doi.org/10.1007/s11926-011-0221-7

PMid:22102179 